\title{
Neuroprotective effect of ziprasidone: Preliminary results compared to haloperidol
}

\author{
Nilgün Çınara , Alper Karaoğlan ${ }^{\mathrm{b}}$, Ahmet Midic, Mehmet Alpay Çal ${ }^{\mathrm{b}}$, Bilal Kelten ${ }^{\mathrm{b}}$, Miraç Ayşen Çakmak ${ }^{\mathrm{a}}$, Şevki Şahin ${ }^{\mathrm{a} *}$ \\ ${ }^{a}$ Department of Neurology, Faculty of Medicine, Maltepe University, Istanbul, Turkey \\ ${ }^{b}$ Department of Neurosurgery, Faculty of Medicine, Maltepe University, Istanbul, Turkey \\ ${ }^{c}$ Department of Pathology, Faculty of Medicine, Maltepe University, Istanbul, Turkey
}

\section{ARTICLE INFO}

\section{Article History}

Received $\quad 21 / 02 / 2014$

Accepted $\quad 10 / 05 / 2014$

\section{* Correspondence to:}

Şevki Şahin

Department of Neurology,

Faculty of Medicine,

Maltepe University,

Istanbul, Turkey

e-mail:drsahin@gmail.com

\section{Keywords:}

Brain ischemia

Haloperidol

Hippocampus

Neuroprotective agents

Ziprasidone

\section{ABSTRACT}

Typical and atypical antipsychotic drugs are widely used to treat psychosis. The present study investigated whether ziprasidone, an atypical antipsychotic drug, has a neuroprotective effect on hippocampal neurons in rats with experimentallyinduced transient cerebral ischemia comparatively with haloperidol which is a typical antipsychotic. Transient cerebral ischemia was induced by 10-minute occlusion of bilateral carotis communis arteries. The rats were divided into four groups: Shamoperated control group (Group I), ischemia control group (Group II), haloperidol-treated group (Group III) and ziprasidone-treated group (Group IV). Following 10-minute ischemia, Group III received $1 \mathrm{mg} / \mathrm{kg}$ haloperidol intramuscularly and Group IV received $2.5 \mathrm{mg} / \mathrm{kg}$ ziprasidone intraperitoneally. The animals were sacrificed on the seventh day following induced ischemia to determine the number of intact neurons at hippocampus and dentate gyrus to demonstrate the effects of ischemia and efficacy of the treatments administered. Surviving cell numbers were found in the sham operated group; 198, in the ischemia control group; 80, in the haloperidol-treated group; 185, in ziprasidonetreated group; 189 . The groups showed significant difference in the comparison of the surviving cell numbers. However, the number of surviving cells did not significantly different between the ziprasidone and haloperidol-treated group. Previous studies with the ischemia model have demonstrated protective effects of haloperidol on hippocampal region. The findings of the present study show that ziprasidone, which is an atypical antipsychotic drug, may produce neuroprotective effects as potent as haloperidol, which is a typical antipsychotic drug.

J.Exp.Clin.Med., 2014; 31:71-75

(C) 2014 OMU

\section{Introduction}

Antipsychotic drugs are widely used in the treatment of schizophrenia. These agents also have some beneficial effects beyond their effectiveness as antipsychotic drugs. Among these effects, they are also considered to have some neuroprotective effects in the brain (Yulug et al., 2006a; Yulug et al., 2006b) Recent in vivo and in vitro experiments have demonstrated that second-generation antipsychotic drugs might also have neuroprotective effects (Park et al., 2006; Park et al., 2009).

The typical antipsychotic drug haloperidol is an antagonist of dopamine sigma-1 receptors and it potently protects neurons against oxidative stress-related cell death in vitro at low concentrations. Some atypical antipsychotics such as olanzapine and risperidone also showed significant neuroprotection after permanent focal cerebral ischemia in previous studies (Roh et al., 2008).

Ziprasidone has a high affinity antagonist activity to dopamine D2 receptors, inverse agonist activity at serotonin 5-hydroxytryptamine (5-HT)2A receptors and agonist activity at 5-HT1 A receptors. It also has a moderate affinity for histamine receptors. There is currently no study on neuroprotective effects of ziprasidone, an atypical antipsychotic drug, approved by the American Food and Drug Administration (FDA) in 2001, regarding its effects in animal ischemia model (Nemeroff et al., 2005).

This study's aim is to investigate the ziprasidone's neuroprotective effects, comparatively with haloperidol, on rat hippocampal neurons in transient focal cerebral ischemia, which is a common disorder in neurology and neurosurgery practices. 


\section{Materials and methods}

Experimental groups

Group I ( $n=5$; Sham-operated control group): In this group, bilateral carotis communis arteries were exposed by a transverse incision at the cervical midline and then the skin was covered with 3-0 silk. After 7 days, perfusion and fixation were performed as described above.

Group II (n=5; Ischemia control group): As in the Group I, bilateral the carotis communis arteries were exposed by a transverse incision in the animals in this group. Bilateral carotis communis arteries were clipped by aneurysm clips for 10 minutes to induce focal cerebral ischemia. The clips were then released to induce reperfusion. The skin was sutured with 3-0 silk. No treatment was administered to the rats in this group. As in the Group I, perfusion and fixation were performed 7 days after the induced ischemia.

Group III (n=5; Ziprasidone treated group): As in the Group II, focal cerebral ischemia was induced by clipping bilateral carotis communis arteries for 10 minutes in this group of animals and one minute after reperfusion, each rat received an intraperitoneal injection of $2.5 \mathrm{mg} / \mathrm{kg}$ ziprasidone. The skin was covered with 3-0 silk. As in the Group II, perfusion and fixation were performed 7 days after the induced ischemia.

Group IV ( $n=5$; Haloperidol treated group): As in the Group III, focal cerebral ischemia and reperfusion was induced in this group of animals, and one minute after reperfusion, each rat received an intramuscular injection of $1.0 \mathrm{mg} / \mathrm{kg}$ haloperidol. The skin was sutured with 3-0 silk. As in the Group III, perfusion and fixation were performed 7 days after the induced ischemia.

\section{Induction of transient focal cerebral ischemia}

The experimental procedures and protocols used in this study were reviewed and approved by our Institutional Committee on Animal Research. The experiments were carried out on twenty adult male Wistar albino rats weighting 250-300g. The animals were starved overnight and anesthesia was induced in rats with intraperitoneal injection of $60 \mathrm{mg} / \mathrm{kg}$ ketamine (Ketalar, Parke-Davis, Eczacıbaşı, Istanbul, Turkey) and $9 \mathrm{mg} / \mathrm{kg}$ Xylazine (Rompun, Bayer, Istanbul, Turkey). Additional doses were administered as needed during surgery. Body temperatures were monitored using a rectal thermometer and was maintained at $37^{\circ} \mathrm{C}$ by heating lamps. The rats were fixed at the supine position. Bilateral the carotis communis arteries were exposed by a transverse incision at the cervical midline and were clipped for 10 minutes period by using Yaşargil Aneurysm Clips. The clips were then released to induce reperfusion. The rats were administered $2.5 \mathrm{mg} / \mathrm{kg}$ ziprasidone (Zeldox, Pfizer, Istanbul, Turkey) inraperitoneally and $1 \mathrm{mg} / \mathrm{kg}$ haloperidol (Norodol, Ali Raif, Istanbul, Turkey) intramuscularly. The doses of these drugs were selected from the study of Park et al (2006). Both the treated and untreated rats were prepared for histopathological analyses after 7 days of ischemia induction. Two hundreds $\mathrm{mL}$ heparinized saline $(0.09 \%)$ was administered through the intracardiac route for perfusion. Fixation was then achieved with formaldehyde $10 \%$ solution with $0.1 \mathrm{M}$ phosphate buffer. Brains were removed as a whole by wide craniectomy and were placed in formaldehyde $10 \%$ solution with $0.1 \mathrm{M}$ phosphate buffer as previously described (Iwasaki et al., 1989; Ozdemir et al., 2013).

\section{Histological evaluation}

Coronal samples were collected from the brain region including the hippocampus $(3.3-3.5 \mathrm{~mm}$ posterior of the bregma). The tissues were monitored for 13 hours in the automated tissue processor (Thermo Shandon Excelsior ES). This process involved treatment of tissues with two cups of formaldehyde, 4 cups of alcohol (70, 80, 95 and 100\%), 2 cups of xylol and 2 cups of paraffin, respectively. After monitoring, the tissues were immersed in paraffin. From the paraffin blocks, serial sections with $4 \mu \mathrm{m}$ thicknesses were collected from the hippocampal regions and dentate gyrus $(3.3-3.5 \mathrm{~mm}$ posterior of the bregma) in rotary type microtome (Thermo Shandon Finesse 325. Massachusetts, A.B.D.). The sections were stained with hematoxylin and eosin to evaluate ischemic changes.

Degenerative changes were analyzed in hypoxic neurons. Nuclear changes (nuclear condensation, nucleoli loss, pyknosis, irregular nuclear membrane) and cytoplasmic changes (cytoplasmic acidophily and vacuolization) were studied. Nuclear changes and cytoplasmic eosinophilia leads to 'red neuron' appearance. Thus, red neurons were evaluated as affected cells while neurons with clear cytoplasm and distinguished nucleoli were taken as unaffected cells. Readings were taken by using the Olympus CX 31 light microscope $\mathrm{x} 10$ option (objective 10, ocular 10). Hippocampus and dentate gyrus regions were analyzed by investigators blinded to experiment groups. All intact neurons in these regions were counted and were averaged.

\section{Statistical analysis}

For statistical analyses, intergroup differences were studied using Kruskal Wallis test. Paired comparisons used Mann Whitney U test with SPSS version 16 (SPSS Inc. Chicago, USA). Statistical significance was set at $\mathrm{p}<0.05$.

\section{Results}

The intact and affected (degenerated) neurons were demonstrated in the developed sections using hematoxylin eosin stain (Fig. 1). Median, minimum and maximum values of neural cell survival in hippocampal regions and dentate gyrus were estimated. Mean number of intact cells was found in the control group 198; in the sham operated group 80; in the haloperidol group 185; in the ziprasidone group 189 (Fig. 2). There are no significant differences between each histological areas according to the number of intact cells $(\mathrm{p}=0.07)$ (Table 1). The comparison of the number of intact cells between 4 groups showed significant difference with Kruskal Wallis test $(\mathrm{p}=0.001)$. The number of surviving cells in both haloperidole and ziprasidone groups were significantly higher compaired with ischemia control group (Group II-III, Group II-IV, $\mathrm{Z}=-2.619, \mathrm{p}=0.009$ ). The number of surviving cells in both haloperidole and ziprasidone groups were significantly lower when compaired with the sham-operated control group (Group I-III, Group I-IV, Z=-2.619, $\mathrm{p}=0.009$ ). However, the number of surviving cells were not significantly different between the ziprasidone and the haloperidol-treated group (Group III-IV, Z $=-1.803, \mathrm{p}=0.07$ ).

\section{Discussion}

Interest in role of neurotransmitters in ischemia resulted in studies establishing that releases of not only glutamate 


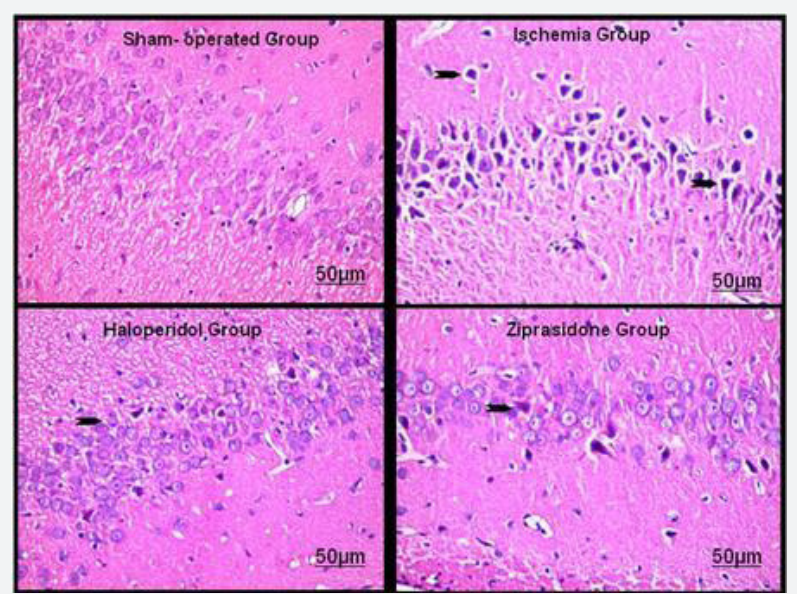

Fig. 1. Photomicrographs showing hippocampal tissue (Cornu Ammonis area) of all groups. Protective effect of ziprasidone and haloperidol against ischemiamediated cell loss in the hippocampus of the rats; arrows indicate location of the affected neurons with homogenous eosinophilic cytoplasm and pycnotic nuclei (hemotoxylen-eosin staining).

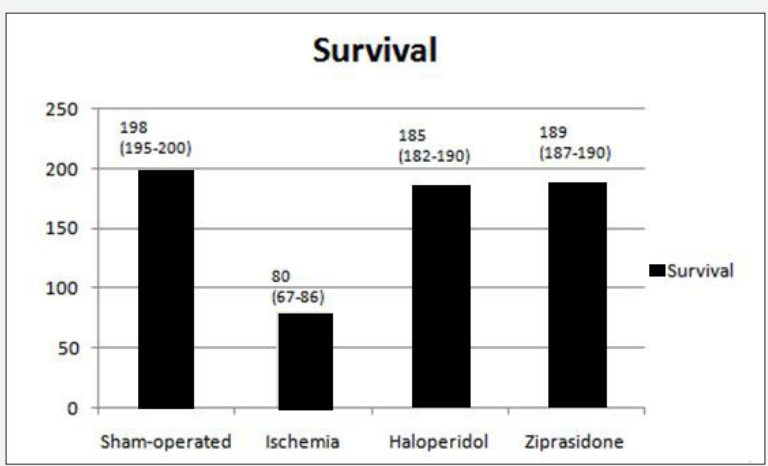

Fig. 2. Median (minimum-maximum) number of intact cells by groups counted at the hippocampus are demonstrated in the figure above.

but also other neurotransmitters are important for the development of ischemic neuronal damage (Globus et al, 1988; Meldrum, 1989). It has been shown that there is a large increase in dopamine and serotonin during ischemia which are involved in ischemic neuronal damage and related to the severity of ischemic insult in the brain (Richards et al., 1993; Hashimoto et al., 1994).

In the light of these findings, it can be hypothesized that antipsychotic agents could prevent or delay cerebral ischemia via their antidopaminergic and antiserotonergic effects. However, the neuroprotective effects of the classical mood stabilizers "lithium and valproate" and clinical evidence suggesting some mood stabilizing effects of the atypical antipsychotics would provide further rationale to investigate neuroprotective effects of these agents after cerebral ischemia (Dunn et al., 1998; Johannessen, 2000). In this respect, the neuroprotective effects of atypical antipsychotic agents have been already shown by several in vivo and in vitro experimental models (Bai et al., 2004).

Previous studies indicate that Sigma-1 receptors are capable of mediating protection against cerebral ischemic stroke (Maurice and Su, 2009). The results of an experimental study indicated that low levels of the antipsychotic drug haloperidol significantly protected against oxidative stressinduced cell death and it might have a novel application as a protective agent against ischemic cerebral stroke and other types of brain injury. This study also suggested that the protective potency of haloperidol positively correlates with their affinity for a Sigma-1 receptor, and the neuroprotection is mediated by antagonizing the Sigma-1 receptors. (Schetz et al., 2007).

In our study, a marked reduction was observed in the average number of affected neurons at the hippocampus and dentate gyrus regions with haloperidol treatment after cerebral ischemia. We believe that, this neuroprotective activity is associated with a similar mechanism.

Ziprasidone is a novel benzisothiazolylpiperazine antipsychotic that shares only modest structural homology with other members of the diverse class of atypical or secondgeneration antipsychotics. Among atypical antipsychotics, ziprasidone is unique in exhibiting inverse agonist activity at serotonin 5-HT2A receptors, agonist activity at 5-HT1A receptors, and antagonist activity at 5-HT1D and 5-HT2C receptors (Schmidt et al., 2001; Shapiro et al., 2003; DeLeon et al., 2004; Nemeroff et al., 2005).

Ziprasidone also differs from other atypical antipsychotics in having a high affinity for the serotonin and norepinephrine transporters. In vitro ziprasidone demonstrates reuptake inhibitory effects that are comparable to imipramine raising the possibility that ziprasidone may both have significant efficacy in the treatment of depressive symptoms, and the ability to promote hippocampal neurogenesis and reduce the neuronal cell loss observed in both affective illness and schizophrenia (Arango et al., 2001; Duman, 2004; Roh et al., 2008).

Among the different 5-HT receptors, the 5-HT1 A receptor subtype seems to attenuate excitotoxicity. Stimulation of the 5-HT1A receptor may play a role in neuronal survival (Raymond et al., 2001; Madhavan et al., 2003). 5-HT1A receptor stimulation rescued cultured hippocampal neurons from glutamate-mediated excitotoxicity and protected against ischemic neuronal cell death (Nakata et al., 1997; Harkany et al., 2001; Madhavan et al., 2003). Previous studies have shown that 5-HT1A receptor stimulation can

Table 1. Comparison of each paired groups with Mann Whitney U test. Statistically significant effects are indicated with asterisks $(*)$

\begin{tabular}{lcccccc} 
Survival cells & Group I & Group II & Group III & Group IV & & p value \\
\hline Median & 198 & 80 & 185 & 189 & Group I- Group II & $0.009^{*}$ \\
(Minimum-maximum) & $195-200$ & $67-86$ & $182-190$ & $187-190$ & Group I- Group III & $0.009 *$ \\
& & & & & Group I- Group IV & $0.009 *$ \\
& & & & Group II- Group III & $0.009 *$ \\
& & & & & Group II- Group IV & $0.009^{*}$ \\
& & & & & Group III- Group IV & $0.070^{*}$ \\
\hline
\end{tabular}


modulate NMDA receptor-induced $\mathrm{Ca}^{2+}$ influx (Strosznajder et al., 1996; Matsuyama et al., 1997; Madhavan et al., 2003). Other mechanisms, in addition to inhibition of N-methylD-aspartate (NMDA)-induced $\mathrm{Ca}^{2+}$ influx, may be important in the neuroprotection resulting from 5-HT1A receptor stimulation. Madhavan et al. suggested that 5-HT1 A receptor stimulation protects against NMDA-mediated apoptotic cell death in both striatal and nigral neurons (Madhavan et al., 2003). Prehn et al. (1993) suggest that 5-HT, released during ischemia, may have protective effects in the pathophysiology of ischemic brain damage through a direct action on neurons mediated via the inhibitory 5-HT1A receptor subtype. Park et al. $(2006 ; 2009)$ suggested that ziprasidone and quetiapine might have effect on the expression of the neuroprotective protein brain-derived neurotrophic factor (BDNF) in the rat hippocampus and neocortex. The present study showed that the number of intact hippocampal cells were significantly higher in the ziprasidone-treated group compared to the controls. This neuroprotective activity may be explained by the agonist activity for 5-HT1A receptors and the effect of BDNF, which were described previously.

This study showed that post-ischemic treatment with haloperidol and ziprasidone reduced the ischemic neuronal damage in the hippocampus and dentate gyrus and provided neuroprotection against transient cerebral ischemia. Comparison of these agents'in terms of the neuroprotective effects was made. However, any statistically significant difference wasn't yield in survival rate of neural cells.

Administration of ziprasidone can be neuroprotective and the potential clinical usefulness of ziprasidone may prevent neuronal loss in the forebrain ischemia. Further experiments to evaluate the long-term clinical reflections of such neuroprotective effects of typical and atypical neuroleptics are needed.

\section{REFERENCES}

Arango, C., Kirkpatrick, B., Koenig, J., 2001. At issue: Stress, hippocampal neuronal turnover, and neuropsychiatric disorders. Schizophr. Bull. 27, 477-480.

Bai, O., Zhang, H., Li, X.M., 2004. Antipsychotic drugs clozapine and olanzapine upregulate bcl-2 mRNA and protein in rat frontal cortex and hippocampus. Brain. Res. 1010, 81-86.

DeLeon, A., Patel, N.C., Crismon, M.L., 2004. Aripiprazole: A comprehensive review of its pharmacology, clinical efficacy, and tolerability. Clin. Ther. 26, 649-666.

Duman, R.S., 2004. Depression: A case of neuronal life and death? Biol. Psychiatry. 56, 140-145.

Dunn, R.T., Frye, M.S., Kimbrell, T.A., Denicoff, K.D., Leverich, G.S., Post, R.M., 1998. The efficacy and use of anticonvulsants in mood disorders. Clin. Neuropharmacol. 21, 215-235.

Globus, M.Y.T., Busto, R., Dietrich, W.D., Martinez, E., Valdes, I., Gingsberg, M.D., 1988. Effect of ischemia on in vivo release of striatal dopamine, glutamate and gamma aminobutyric acid studies by intracerebral microdialysis. J. Neurochem. 51, 1455-1464.

Harkany, T., Mulder, J., Horvath, K.M., Keijser, J., van der Meeberg, E.K., Nyakas, C., Luiten, P.G., 2001. Oral post-lesion administration of 5-HT(1A) receptor agonist repinotan hydrochloride (BAYx3702) attenuates NMDA-induced delayed neuronal death in rat magnocellular nucleus basalis. Neuroscience. 108, 629-642.

Hashimoto, N., Matsumumoto, T., Mabe, H., Hashitaní, T., Nishino, H., 1994. Dopamine has inhibitory and accelerating effects on ischemia induced neuronal cell damage in the striatum. Brain. Res. Bull. 33, 281-288.

Iwasaki, Y., Ito, S., Suzuki, M., Nagahori, T., Yamamoto, T., Konno, H., 1989. Forebrain ischemia induced by temporary bilateral common carotid occlusion in normotensive rats. J. Neurol. Sci. 90, 155-165.

Johannessen, C.U., 2000. Mechanisms of action of valproate: A commendatory. Neurochem. Int. 37, 103-110.

Madhavan, L., Freed, W.J., Anantharam, V., Kanthasamy, A.G., 2003. 5-Hydroxytryptamine 1A receptor activation protects against N-Methyl-daspartate-induced apoptotic cell death in striatal and mesencephalic cultures. J. Pharmacol. Exp. Ther. 304, 913-923.

Matsuyama, S., Nei, K., Tanaka, C., 1997. Regulation of GABA release via NMDA and 5-HT1A receptors in guinea pig dentate gyrus. Brain. Res. 761, 105-112.

Maurice, T., Su, T.P., 2009. The pharmacology of sigma-1 receptors. Pharmacol. Ther. 124, 195-206.

Meldrum, B., 1989. Excitotoxicity in ischemia. An overview. In: M.D. Ginsberg and W.D. Dietrich, Editors. Cerebrovascular Diseases. Sixteenth Research (Princeton) Conference Raven Press, New York. p.p. 47-60.

Nakata, N., Suda, H., Izumi, J., Tanaka, Y., Ikeda, Y., Kato, H., Itoyama, Y., Kogure, K., 1997. Role of hippocampal serotonergic neurons in ischemic neuronal death. Behav. Brain. Res. 83, 217-220.

Nemeroff, C.B., Lieberman, J.A., Weiden, P.J., Weiden, P.J., Harvey, P.D., Newcomer, J.W., Schatzberg, A.F., Kilts, C.D., Daniel, D.G., 2005. From clinical research to clinical practice: A 4-year review of ziprasidone. CNS. Spectr. 10, 1-20.

Ozdemir, H.H., Demir, C.F., Berilgen, M.S., Akgun, B., Kuloğlu, T., Kapan, O., Ilhan, S., Balduz, M., 2013. Protective effects of memantine in experimentally induced cerebral ischemia and reperfusion injury in rats. Türk. Nörol. Derg. 19, 85-89.

Park, S.W., Lee, S.K., Kim, J.M., Yoon, J.S., Kim, Y.H., 2006. Effects of quetiapine on the brain-derived neurotrophic factor expression in the hippocampus and neocortex of rats. Neurosci. Lett. 402, 25-29.

Park, S.W., Lee, C.H., Lee, J.G., Lee, S.J., Kim, N.R., Choi, S.M., Kim, Y.H., 2009. Differential effects of ziprasidone and haloperidol on immobilization stress-induced mRNA BDNF expression in the hippocampus and neocortex of rats. J. Psychiatr. Res. 43, 274-281. doi: 10.1016/j.jpsychires.2008.05.010.

Prehn, J.H.M., Welsch, M., Backhauss, C., Nuglisch, J., Ausmeier, F., Karkoutly, C., Krieglstein, J., 1993. Effects of serotonergic drugs in experimental brain ischemia: Evidence for a protective role of serotonin in cerebral ischemia. Brain Research. 630, 10-20.

Raymond, J.R., Mukhin, Y.V., Gelasco, A., Nuglisch, J., Ausmeier, F., Karkoutly, C., Krieglstein, J., 2001. Multiplicity of mechanisms of serotonin receptor signal transduction. Pharmacol. Ther. 92, 179-212.

Richards, D.A., Orenovich, T.P., Symon, L., Curzon, G., 1993. Extracellular dopamine and seratonin in the rat striatum during transient ischemia of different severities: A microdialysis study. J. Neurochem. 60, 128-136.

Roh, K., Roh, S., Yang, B.H., Lee, J.S., Chai, Y.G., Choi, M.R., Park, Y.C., Kim, D.J., Kim, D., Choi, J., Kim, S.H., 2008. Effects of haloperidol and risperidone on the expression of heat shock protein 70 in MK-801-treated rat C6 glioma cells. Prog. Neuropsychopharmacol Biol. Psychiatry. 32, 1793-1797. doi: 10.1016/j.pnpbp.2008.07.018. 
Schetz, J.A., Perez, E., Liu, R., Chen, S., Lee, I., Simpkins, J.W., 2007. A prototypical Sigma-1 receptor antagonist protects against brain ischemia. Brain. Res. 1181, 1-9.

Schmidt, A.W., Lebel, L.A., Howard, H.R. Jr, Zorn, S.H., 2001. Ziprasidone: A novel antipsychotic agent with a unique human receptor binding profile. Eur. J. Pharmacol. 425, 197-201.

Shapiro, D.A., Renock, S., Arrington, E., 2003. Aripiprazole, a novel atypical antipsychotic drug with a unique and robust pharmacology. Neuropsychopharmacol. 28, 1400-1411.

Strosznajder, J., Chalimoniuk, M., Samochocki, M., 1996. Activation of serotonergic 5-HT1A receptor reduces Ca(2+)- and glutamatergic receptor-evoked arachidonic acid and No/cGMP release in adult hippocampus. Neurochem. Int. 28, 439-444.

Yulug, B., Yildiz, A., Guzel, O., Kilic, E., Schäbitz, W.R., Kilic, E., 2006a. Risperidone attenuates brain damage after focal cerebral ischemia in vivo. Brain. Res. Bull. 69, 656-659.

Yulug, B., Yildiz, A., Hudaoglu, O., Kilic, E., Cam, E., Schäbitz, W.R., 2006b. Olanzapine attenuates brain damage after focal cerebral ischemia in vivo. Brain. Res. Bull. 71, 296-300. 